\title{
Personalisation and CRM
}

Received (in revised form): 5th November, 2007

\section{Tyrone W. Jackson}

is an associate professor in Marketing at California State University, Los Angeles. He has more than 17 years of industry experience working with Global 500 companies. He has held senior management positions for global management consulting firms, Accenture and KPMG Consulting (BearingPoint). His areas of expertise are in direct marketing, data mining, analytics, CRM and business intelligence. He earned his MA from Yale University in Economics; and MS and PhD in Marketing Science and Econometrics at the University of California at Berkeley.

Keywords personalisation, CRM, anticipating relevant intent, acquisition, growth, retention

\begin{abstract}
Personalisation has been utilised by various companies in the electronic marketplace. Gartner research stated that by 2004, 80 per cent of content-rich IT applications (eg news sites, e-tailers and corporate intranets) will incorporate personalisation. Personalisation is becoming more of an increasing segment of the internet economy. Customer relationship management (CRM) has been an accepted strategy of companies in order to improve their performance. The concept of personalisation and CRM has expanded in scope to emphasise a much broader notion of benefits to a company. The focus of this paper is to determine whether companies can increase the return generated by their electronic commerce strategy by utilising 'personalisation' in executing CRM in the electronic marketplace. A case-study approach was utilised to identify personalisation strategies and its benefits. Lessons learned from the cases examined revealed that companies should approach personalisation from an inter-functional as opposed to a 'silo' implementation to reap maximal benefits. Our research found that competitive pressures and cost savings helped to spurn the use of personalisation. Personalisation requires 'anticipating relevant intent' of customers in order to increase benefits. Other key findings identified that companies, both business to business (b2b) and business to consumers (b2c), employing personalisation improves the benefits of CRM. Journal of Database Marketing \& Customer Strategy Management (2007) 15, 24-36 doi:10.1057/palgrave.dbm.3250065; published online 3 December 2007
\end{abstract}

\section{INTRODUCTION}

Personalisation is viewed as the means by which content on the web can be tailored on a website for every visitor. In this manner it differentiates itself in how business is done in the real world. Various analysts and experts believe that personalisation is the key to the future of the E-Commerce revolution. Personalisation represents the best chance for survival for online merchandisers according to Marc Singer, author of Net Worth and an analyst with McKinsey \& Co., 'Getting [personalisation] right will be the difference between life and death for a lot of the online pure-play commerce companies. ${ }^{1}$ Personalisation alone, however, will not be a panacea for companies looking to grow and retain customers. Personalisation must be an integral part of a broader strategy in order for companies to succeed.

The topics of personalisation and customer relationship management (CRM) are complementary to each other. CRM is viewed as a strategy to attract, grow and retain customers. ${ }^{2}$ Personalisation is an 
approach that can aid in bringing, staying and returning - visitors/customers - to a website. They both have the capability of providing the right information or content (eg products, services and data) to the enduser/customer at the right time and right place. Both provide a customised outcome for customers that can lead to competitive advantage for firms using either personalisation or CRM. The challenge is to incorporate personalisation with CRM to maximise the benefits. The concept of personalisation and CRM has expanded in scope to emphasise a much broader notion of benefits to a company.

The paper is organised as follows: we first present a summary discussion of personalisation. We then discuss whether personalisation is a process or technology. We then describe how companies can evolve to personalisation in the context of CRM. We then present three case studies of companies using personalisation. We then examine the lessons learned and some examples from both business-to-business (b2b) and business-to-customers (b2c) companies of the use of personalisation. Personalisation benefits in the context of
CRM as well as some of the metrics being used in the marketplace are then presented. The paper then offers recommendations for future research in this area. Finally, the paper concludes with a summary of the key findings.

\section{WHAT IS PERSONALISATION?}

A January 2001 Gartner Research Note stated that by 2004,80 per cent of contentrich IT applications (eg news sites, e-tailers and corporate intranets) will incorporate personalisation. ${ }^{3}$ The Personalisation Consortium, a group of companies dedicated to the personalisation of technology for business and customer relationships, recently reported that 63 per cent of US consumers are more likely to register at a website that accommodates content customisation and offers personalisation features. ${ }^{4}$ Personalisation is a rapidly growing area via electronic media. This paper refers to personalisation as utilising the information acquired through a user's interaction with an electronic interface to increase the value of current and future user interactions. Namely, personalisation is not only about delivering

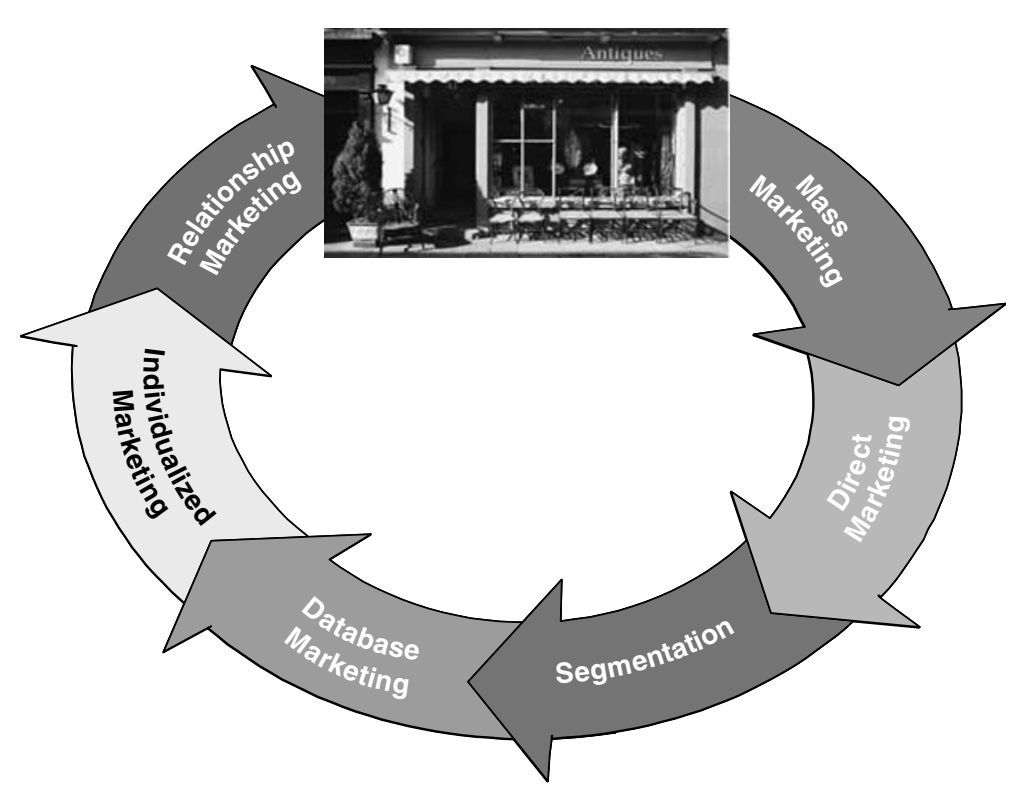

Figure 1: Changing personalisation trends of the neighbourhood merchant 
communication - whether it is pure information, product and/or services, but personalisation must provide these various types of information when 'anticipating relevant intent' of customers at the right time and at the right place.

Industry forces are driving businesses to maximise the value of each customer interaction through differentiated marketing, sales and service. For instance, some of the marketplace trends include: retention of their customers in order to achieve mutual long-term value and benefits. ${ }^{5}$ However to deliver or implement CRM it consists of strategy, people, process, technology, analysis and tools. ${ }^{6}$

Personalisation as CRM has both process and technology components as well as data that are transformed by models to provide valuable information to yield an interaction that builds relationships between a company and its customers.
- Differentiate customer treatment based on value

- Coordinate offers across brands and channels

- Provide individualised marketing offers throughout customer lifetime

- Additional external information

- Increased segmentation and modelling

- Varying offers based on perceived value to customer

- Coordinated offers across brands/channels

- Multiple channel execution

- Extensive use of relational database in storing customers' behaviour
- Beginning to utilise past behaviour in solicitation decisions

- Brand awareness

- Mass promotions/advertising

- Measurement on attitudes/Not behaviour

- Individualised marketing

- Moving from occupant/resident to a person's name

- Extensive use of Lists

- Specific product or large customer group marketing

- Use of niche media based on preference of target customer group(s)
The neighbourhood merchant concept that provided personalisation has given way to newer trends in the marketplace that have reshaped what personalised service means especially via the internet. In as much personalisation is about relevance. Namely, businesses will need to make their websites more relevant to people based upon the interactions between both parties. Some of the personalisation trends are depicted in Figure 1.

Personalisation is not a thing but rather a way of doing things. Personalisation derives customer information to provide consistent, timely and relevant individualised interactions and offers to each customer across all touchpoints that increases customer loyalty and lifetime value.

\section{PERSONALISATION - PROCESS OR TECHNOLOGY}

Personalisation is a part of CRM. CRM is

a business strategy for managing a company's acquisition, development, and
Personalisation is the process of emulating social processes to provide recommendations based on an understanding of one's preferences. One of the technologies to deliver personalised content is collaborative filtering. Personalisation is a process that continually adjusts profiles to match targeted content with individuals. From a process and technology perspective, personalisation can be classified into two categories 'push' and 'pull'. Push is where the content is sent to the user. Pull is where the user goes to look for the content. For push technology, the end-user does not have to be present. Companies can use information delivery, event reminders and information updates as a part of their push technology. Early versions of the 'push' technology on the web can be seen at websites such as PointCast.

\section{EVOLVING TO PERSONALISATION}

Personalisation via the electronic channel has evolved from basic levels of customer 
Table 1: Stages of personalisation

\begin{tabular}{llll}
\hline & Basic & Advanced & Compelling \\
\hline User profile & Manual update & $\begin{array}{l}\text { Manual with some automatic } \\
\text { update }\end{array}$ & Automatic, dynamic update \\
$\begin{array}{lll}\text { Richness of experience } \\
\text { Span }\end{array}$ & Low & $\begin{array}{l}\text { High } \\
\text { Multiple sites in bounded } \\
\text { Communities }\end{array}$ & Extreme \\
& & Universal & \\
\hline
\end{tabular}

Source: Forrester Research. ${ }^{8}$

Table 2: Phases of personalisation implementation

\begin{tabular}{lll}
\hline Phase I & Phase II & Phase III \\
\hline Basic & Intermediate & Advanced \\
$\begin{array}{l}\text { Customer recognition } \\
\begin{array}{l}\text { Mail or website addressed to the } \\
\text { individual }\end{array}\end{array}$ & $\begin{array}{l}\text { Customer provided } \\
\text { User-provided information } \\
\text { from surveys, registration } \\
\text { forms, etc }\end{array}$ & $\begin{array}{l}\text { Preference-based personalisation } \\
\text { Tracking user activity, comparing that activity } \\
\text { with other users' behaviour and predicting } \\
\text { what the user would like to see next }\end{array}$ \\
\hline
\end{tabular}

interaction. For example, early websites were considered 'personalised' if they recognised the user by name upon login or provided order information by entering a unique customer number. Peppers and Rogers, coauthors of Enterprise One to One, expressed the future implications of this personalisation technology: the appliances and machines around us will soon remember us individually and anticipate our needs. ${ }^{7}$ Amazon was an early pioneer of this technology in building suggestive 'I know you' communication via an electronic channel by interacting and recommending similar or like products to customers through the use of 'collaborative filtering' technology. Ultimately, personalisation is achieved if the customer feels that what is being communicated is 'Just For Me.' The various stages of personalisation are represented in Table 1.

Most companies go through an implementation-phased approach for personalisation. This includes utilising data, analysis and modelling in deriving information about a customer's preference to allow a more targeted value proposition. The various phases of personalisation information are depicted in Table 2.
There are many types and levels of online personalisation that can be utilised. There are six specific characteristics that are necessary for a site to be considered 'personalised', which include:

1 Identification - The first step is user identification. This enables the remaining components of the personalisation process.

2 Data capture - Collection of data about the user can be carried out through implicit and explicit techniques. The objective is to capture information that will assist in determining and delivering future content.

3 Analysis and refinement - Once data are captured, the system needs to analyse the data and draw insights about the information and interaction. This is generally done real-time, while the user is navigating the site.

4 Match - After a number of user interactions, a 'Personalisation Matching Factor' is established based on rules (eg who, what, where, when, why). These factors assist in creating a user profile.

5 Merge and delivery - Upon determining the proper interface and content, 
the system merges and delivers the information to the user.

6 Optimisation - The true potential of personalisation is realised over a period of time. As the number of interactions increase, and the above five steps are repeated, a better understanding of the user's profile evolves, further improving the effectiveness of the technology.

Two common personalisation technologies are 'rules-based-matching', which creates user profiles based on user preferences and information requests, and 'collaborative filtering', which sorts previously created profiles into affinity groups to infer what the customers' needs may be. The important distinction between the two is that rulesbased-matching is established directly by the user while collaborative filtering adopts a more automated 'black box' approach. Although the two approaches can be complementary, rules-based-matching continues to be more prevalent due to its simplicity. ${ }^{9}$ At American Airlines, for example, users must currently log in to receive the benefits of a personalised site. Log-in requires the user to enter basic demographic and travel preference data. The site also uses personalised messaging, content, account management and travel planning. The current rules-based-matching experience includes receiving an electronic newsletter by email that includes special offers and news based on information specified by the user through a discrete query. As the site develops, a shift to a collaborative filtering approach would incorporate an automated process recognising that a user inquired about flights to a specific location, say Fiji, at approximately the same time of the year, for example, December, for several years. Subsequently, the user receives an email in late November announcing a special vacation package to Fiji.

The two developing personalisation schemes are: content-based filtering and systems based on web usage mining (WUM). An example of a content-based filtering system is News Dude. ${ }^{10}$ The system identifies and learns its user's news story preferences through a form and analyses the data along with the content of news articles already read to suggest relevant articles. The personalisation systems using WUM such as web personaliser ${ }^{11}$ and adaptive websites ${ }^{12}$ are becoming popular. These systems incorporate data mining techniques to discover interesting patterns in web-usage data. The downside for the content-based filtering and WUM personalisation schemes is that these are intrusive in nature.

Cisco also realised the capabilities of internet-enabled customer assistance when they implemented a dynamic online knowledge-database called 'My CCO' to reduce the demand for employees via the call centre. Managers saw that the number one reason why customers contacted the call centre was to inquire about the status of an order. This provided an opportunity to personalise the online experience by allowing customers to monitor the status of an order online. This functionality soon led to other capabilities, such as accessing order history, looking at pricing, lead times, renewing service contracts and obtaining technical assistance through a customised user interface with links to the information that the customer is most interested in. Today, 77 per cent of all Cisco's technical cases are resolved through the internet without human interaction, with customers referred to an engineer only if they are unable to find the information online. There are currently about 60,000 external users registered on Cisco's CCO. CCO receives five to six million hits a day and about 75 per cent of all orders are entered electronically through the CCO site. Cisco estimated earnings in FY 1999 of between $\$ 10$ and 12 billion with as much as 80 per cent generated through the web. ${ }^{13}$ 


\section{CASE STUDIES}

With personalisation being used by various companies in the marketplace, the results have been mixed. Not all companies have realised the expected benefits of personalisation that some companies have stated. We present three case studies of companies who operate in the financial services - Sampos Bankas, packaged goods transportation - UPS and airlines industries - American Airlines. These three companies have integrated personalisation within the context of a CRM approach. In addition, all three companies are implementing personalisation from an inter-functional as opposed to a 'silo' implementation to reap maximal benefits. One company in particular, American Airlines, is successfully 'anticipating relevant intent' of its customers within their personalisation implementation approach.

\section{Financial services case study: Sampo Bankas - Personalises products and services}

Sampo Bankas, the third largest bank in Finland with over 1.1 million customers, differentiates itself by personalising its products. The bank sells mortgages and loans, as well as some private banking services, to businesses and consumers. It reaches most of its customers through electronic banking, advertising and through its branch network when customers come in to apply for a loan or make a transaction.

Sampo has no franchise or dominant market position, no proprietary technology and no magic training programme. "Almost all banks are selling the same products.

There are two differentiators: flexibility and speed,' says Norbertas Zioba, the bank's business development director and a board member. ${ }^{14}$ By flexibility, he means personalised solutions that suit the individual customer's needs. By speed, he means the time taken to approve a customer's mortgage.
Sampo Bank for the last three years has been the fastest-growing bank in Lithuania. The results are largely from its personalisation strategies, which it has masterfully applied with a mix of common sense and the use of appropriate technology. For example, in fast-growing Lithuania, people often want to buy an apartment in a house that is not built yet. Competing banks would not approve a loan unless it was backed by hard assets, but Sampo finds other ways to achieve its customers' objectives. It accepts co-signatories, gets an employer to guarantee the loan or even works with the contractors to deposit cash into the applicant's bank account against a letter of credit. The question is how to optimise costs while doing this. Sampo accomplishes this through its branches, as well as with technologies such as CRM programmes, mobile telephony and e-banking. The branches, however, are the most critical, because they enable Sampo to give customers its full attention. By shifting from transactions (currency exchange, loan repayment) to customer interactions (up-selling from mortgage to life insurance, credit cards, car lease), the branches have greatly increased sales of new products to existing customers.

Sampo develops a set of 'pre-customised' solutions to choose from and can anticipate customer needs. For example Sampo can tell customers what changes in pensionsinsurance taxation will mean to them, and remind them what kinds of documentation they need to send in with their tax return. 'Since we know a lot about our customers, and can reach them easily, we can send them tailored details for their tax return at the end of the tax year,' says Minna Suo, Director, Group Marketing and CRM. It now personalises 80 per cent of its solutions by picking options from this menu. ${ }^{15}$ Banking is made convenient and personalised so that its customers with GSM phones can find out their account balances and make transfers while on the 
run. Seventy-five per cent of the Lithuanian population uses GSM phones, and 15 per cent use Short Message Systems (SMS) Banking.

\section{Packaged goods transportation case study: UPS speeds towards personalised logistics}

How do you ensure each of your 7.9 million customers feels like they are your only customer? 'Our long-term strategy,' says Donna Barrett, technology manager UPS (Atlanta), 'is to establish environments in which we create more personalised experiences for the customers. Technology is the great enabler of that strategy.' And since the package delivery person is the company face most customers see, personalisation has to start with him or her. Whether package delivery is viewed as the beginning or the end of the personalisation process, sortation, getting the right package to the right place at the right time, is the element that makes it possible. ${ }^{16}$

Years ago, transportation was hardly likely to be personalised. The train left, the truck drove and the ship sailed whether your cargo was on it or not. But today, UPS, the US-based global transportation giant, offers personalised services across the entire supply chain. Companies of any size or within any market segment can find the logistics solution that best fits their needs. UPS is a leader in using technology to transform the packaged transportation to compete in the new world economy. A key part of that technology transformation at UPS is the programme called Package Flow Technologies (PFT). It has at its centre, daily sortation of millions of packages down to a granular level unknown in most areas of material handling. Along with productivity improvements and cost reductions, the PFT programme will, in the long term, says Barrett, allow drivers to focus more on being a service provider and developer of customer relationships than they are currently. In addition, it allows customers to review the status and track the order with accuracy down to three feet. UPS handles 55 per cent of all online purchases, versus 10 per cent for FedEx, its closest competitor. 'UPS is doing things in e-commerce that other companies are just starting to talk about,' says Jack R. Staff, chief economist at Zona Research in Redwood City, California. ${ }^{17}$ UPS has invested $\$ 600$ million in the PFT initiative to optimise its domestic package network. When the process is complete in 2007, it expects to realise annual cost savings of $\$ 600$ million. $^{18}$

UPS bases its operations on one-to-one relationships with its customers, according to Jordan Colletta, the company's vice president of customer technology marketing. This strategy has apparently paid off: UPS tops the list for trustworthiness in a nationwide survey of companies. A recent customer service study by BusinessWeek ranks UPS as one of the top client-pleasing brands. ${ }^{11}$ In addition, according to the 2006 Annual Reputation Quotient (RQSM), a survey by Harris Interactive that measures the reputations of the US's most visible companies, UPS ranks No. 1 for people's 'trust in the company to do the right thing in the event of a product/service problem, excellent customer service, and sincerity of corporate communications among US companies'. 19

To achieve this desirable rapport with customers, UPS deploys both technologybased services and people-intensive solutions. In both cases, it leverages technology and financial tools to deliver results. For lower-volume shippers, a Solution Finder on UPS's home page offers guidance on the service and degree of 'touch' appropriate for their role, industry, problem and type of shipment. For example, customers shipping internationally need to know whether the consignee is on a prohibited list, customs filing requirements and how to calculate landed cost, including duties, shipping and taxes. 'If you're doing 
this without technology, you're either guessing or you're not including all the relevant costs,' says Mr Colletta. Highervolume shippers are assigned account representatives who work across the UPS Supply Chain Solutions group to engineer the ideal solution. For example, if the customer needs to reduce cost, UPS might find a solution that involves less shipping activity. The account manager consults a solution developer before meeting with the client, and can view the solution through a CRM application before talking to the client. For heavy-volume customers, UPS handles everything in a totally personalised way so that the customers can focus on their core competence. Often, these solutions become embedded in the customers' third-party applications.

UPS customers trust them because the company knows their needs individually. As in any relationship, intimacy and trust are interrelated: customers will not share enough information to allow personalisation until they trust the provider, but they will not trust the provider until it demonstrates an intimate knowledge of their operations. UPS has become expert at building trust and intimacy. It identifies customers' preferences as 'high-touch' or 'low-touch'. 'Some customers are high-tech, savvy, digest information quickly and they want to just go,' says Mr Colletta. 'Others would rather call you or get the one answer they need, then leave.' UPS systematically uses its magic to sense and respond to customers' needs. The company operates on an 'ears, hands and brain' principle: the ears understand the customer, the hands quantify the problem and design a solution and the brain integrates and tests technologies that embed the solution. Such a coordination puts UPS in the enviable position of being able to use customer information to improve each subsequent interaction. Ironically, customers would not identify personalisation as their reason for selecting the company. While the personalisation is invisible, its results address customers' needs more precisely, which keeps customers coming back, according to Mr Colletta. ${ }^{14}$

\section{Airlines case study: American Airlines - Really knows how you fly}

American Airlines (AA), the largest airline in the world in terms of passengers transported, replaced its existing look, based around different company departments, with a personalised site that serves up custom flight discounts tailored to each customers' buying habits. The team also built a user interface for the complex Sabre reservations system to offer an easy-to-use travel planning and ticketing service. The result: a website that now draws 6.9 million unique visits per month and attracts the cream of American's crop: the most frequent users of its rewards programme. The efforts by one of the country's leading airlines demonstrate the process necessary to reengineer a complex website but also to integrate and maintain a highly personalised system.

The first American Airlines website went up in the spring 1995. At that time, the site was simply what Scott Hyden, American Airlines managing director of interactive marketing, called 'brochureware'. The site explained the company but did not offer any interactive services, he says. The site had grown up organically, he adds, organising its pages by the different departments in the company. 'The functionality and user experience were quite limited,' he says. 'There were more than 3,000 HTML pages on the site. We knew we needed to improve in a lot of areas.' American Airlines already maintains a database of 38 million people for its American Advantage (AAdvantage) frequent flyer programme, which gives them a wealth of information on their customers. ${ }^{20}$ Officials also knew that customers liked the company's email programme, which automatically sent out information about discounted fares.

The challenge for AA was how to migrate AA's customers to create a more 
intimate feel for them and to increase customer loyalty, satisfaction while also instilling a CRM approach of acquiring, growing and retaining customers. Rather than focus the site around departments at American in an informational structure, the team wanted the new design to be an extension of the kinds of things customers would naturally want to do on an American Airlines website. They settled on some basic needs: managing the AAdvantage account, booking reservations and finding special fares. To present this information most effectively, they decided that one-to-one marketing was in order.

The first order of business was to decide what kind of information would be personalised and how it would be organised. In American's case, the group chose personalising by airport and purchasing habits. Under this plan, the system remembers the registered users' preferred airport and automatically enters it in the reservations system. It also organises fare discounts by location, presenting only those discounts applicable to the customer's chosen departure location. But the system had one flaw. Some customers live by out-of-the-way airports, resulting in little or no relevant discounts being displayed. 'The content management is difficult when you take on personalisation,' says Hyden. 'If you target content to the wrong customer, you might as well do broadbased marketing.' The group solved the problem by setting up the customisation to display discounts in surrounding areas.

AA's site receives approximately 1.2 million visits on an average weekday. ${ }^{21}$ AA's new site generated 25 per cent more revenue in the months immediately after its implementation than the previous site ever earned in the same timeframe. Customers can now book a flight in as few as five page views and average less than $5 \mathrm{~min}$ per booking - a reduction of 60 per cent. ${ }^{20}$ AA's customers who $\log$ in to their website with their frequent flier number and password can manage their account online and also receive personalised news and specials. A specific example of this personalisation can be seen in the integration of web and phone to anticipate the relevance of your needs. AA's customer can opt in so that their cell phone is recognised, identified and authenticated. AA's new website uses multiple personalisation techniques. A series of dynamic features are used to create a highly personalised experience. Some of the personalisation features include greeting by name and context-specific menus - so that customers are offered appropriate choices at any point. The other key element in the next generation of personalisation experience is 'anticipating relevance intent'. AA's personalisation application looks at your current status to see whether you are flying; whether you are between legs of a trip; whether you have just landed; whether you have got an upcoming return flight, etc. On top of your status is event-based information - are planes late, have you been re-booked, are your bags lost. The combination of these may result in a high probability reason for a phone call by AA to the customer. Anticipating relevant intent allows AA to offer service without having to present a menu selection. This is very forward-thinking and breaks significant new ground for a phone system. This is the phone system of the future, here today.

Today AA is ranked first among USbased Airline websites. ${ }^{22}$ A key criterion used in the ranking was the expanding personalisation efforts on the home page and throughout the booking process, improving CRM efforts in the up- and cross-sell offers. AA has a good detailed understanding of who is their customer and what their needs and wants are as they navigate the site.

\section{LESSONS LEARNED}

When we look across previous personalisation case studies, we find that 
Table 3: Personalisation cost savings

\begin{tabular}{|c|c|}
\hline Company & Results \\
\hline Cisco Systems & $\begin{array}{l}\text { - Saved } \$ 500,000 \text { per month by moving inbound telephone calls from a } \\
\text { human-manned call centre to a look-up utility on the web. } \\
\text { - Saves more than } \$ 700 \text { million annual by moving order inquiries from an inbound call } \\
\text { centre to web pages. }\end{array}$ \\
\hline United Technologies & $\begin{array}{l}\text { - United Technologies saved } 40 \text { per cent on supplies by purchasing them through a } \\
\text { Web auction hosted by FreeMarkets. }{ }^{26}\end{array}$ \\
\hline American Airlines & $\begin{array}{l}\text { - Improved the level of service by making it easier for customers to handle their travel } \\
\text { needs from one location by making the information relevant to the particular } \\
\text { customer, and giving customers control over their own 'account'. }{ }^{25} \\
\text { - ROI projections for personalisation were forecasted to be } 193.5 \text { per cent. }{ }^{27}\end{array}$ \\
\hline
\end{tabular}

although personalisation is a fast-evolving e-commerce strategy, it is not a cure-all for companies conducting business on the web. The industry in which a company operates appears to affect the value of personalisation. For example, companies operating in industries like financial services, computer goods, transportation, entertainment and travel benefit from personalisation because the technology allows them to extend their customer service online. Indeed, the fact that these companies account for more than 80 per cent of the online retail market supports this idea. ${ }^{4}$

Deriving financial figures is especially difficult for b2c e-commerce, as many of these firms have limited customer-specific purchase history. Companies engaged in $\mathrm{b} 2 \mathrm{~b}$ e-commerce, however, appear to have a greater amount of purchasing data, and are more capable of quantifying the overall benefits of personalisation.

Secondary research identifies customer satisfaction as a factor in using personalisation. An article covering Art Technology Group's collaboration with Scudder Kemper Investments to develop a new personal investment organiser for Scudder's clients stated, 'personalisation is the component that transforms e-commerce into Relationship Commerce, enabling businesses to manage the entire customer lifecycle and foster profitable, long-standing customer relationships... The result is increased revenue, better margins, increased customer retention, and improved customer satisfaction'. ${ }^{23}$ Levi Strauss \& Co. stated that after launching the collaborativefiltering-based Levi Strauss Style Finder on its website, the company found that 74 per cent of consumers tested agreed that the clothing recommended to them by the style finder was 'right' for them. ${ }^{24}$ From the experiences of American, Cisco and others, it seems that personalisation can increase customer satisfaction.

The case studies reveal that companies achieved an increase in their CRM efforts from personalisation when:

- IT should not be responsible for the personalisation strategy.

- IT, marketing and the business departments work together.

- The personalisation strategy must be integrated with the enterprise's existing technology and eCommerce Strategies.

\section{PERSONALISATION BENEFITS}

Personalisation results in both qualitative and quantitative benefits for companies proportional to the level of personalisation and their industry positioning. The benefits that will accrue to the company are among the most important factors ever identified as meeting CRM objectives of acquiring, developing and retaining customers. 
Table 4: Revenue generation-induced metrics

\begin{tabular}{llll}
\hline Rank & Site & Conversion rate & Personalisation \\
\hline 1 & Amazon.com & 8.3 & Yes \\
2 & Drugstore.com & 7.9 & Yes \\
3 & QVC & 7.1 & Yes \\
4 & Land's End & 6.3 & Yes \\
5 & CD Now & 6.2 & Yes \\
6 & TicketMaster & 5.7 & Yes \\
7 & BMG Music & 4.8 & Yes \\
8 & Beyond.com & 4.5 & No \\
9 & Reel.com & 3.5 & No \\
10 & J.Crew & 3.4 & No \\
\hline
\end{tabular}

Source: NetPerceptions.

\section{Qualitative benefits}

Qualitative results, such as increased customer loyalty and increased share of customer, while not directly measurable at the bottom line, are critical to the longterm viability of any firm.

Other qualitative benefits as reported by companies include:

- increased customer loyalty

— increased brand awareness

— increased share of customer

- increased switching costs/effort of choosing a competitor's offerings

- increased customer satisfaction scores

— increased number of referrals.

\section{Quantitative benefits}

Personalisation can be quantitatively measured and associated with improving the bottom line. Cost saving metrics utilised for the electronic marketplace have suggested determining the number of 'self-serviced' customers on the web and estimate the cost savings in terms of reduced telephone calls. ${ }^{25}$ Examples of quantitative results include cost savings and revenue generations. Personalisation benefits are reporting more qualitative rather than quantitative benefits. Of those reporting quantitative results, cost savings is the most successful web-initiated revenue producer (see Table 3). Cisco, for instance, learned that it could save money by moving inbound telephone calls from a humanmanned call centre to a look-up utility on the web. The result was faster results to inquiries to Cisco's customers and an increase in customer satisfaction.

Although not as widespread as cost savings as a bottom-line contributor, revenue generation is the next hurdle for web-based personalisation. Table 4 compares the conversion rates for companies that use personalisation as compared to companies that do not use personalisation technology. The stark contrast in conversion rates for the top two companies that use personalisation technology, Amazon.com and Drugstore.com, as compared to the bottom two companies that do not use personalisation technology, Reel.com and J.Crew, is significant.

Other metrics utilised to identify the benefits of personalisation technology is the Personalisation Index. A Personalisation Index distinguishes how well an organisation is using the data they are gathering. The metric is calculated as follows:

\begin{tabular}{lc} 
Personalisation & $\begin{array}{c}\text { Total \# of Profile Elements Used } \\
\text { in Customer Interaction }\end{array}$ \\
\cline { 2 - 3 } & $\begin{array}{c}\text { Total \# of Customer Profile } \\
\text { Elements Collected }\end{array}$
\end{tabular}

Source - Net Genesis ${ }^{28}$

The Personalisation Index (PI) formula assumes that you are using a significant number of elements (name, address, IP address, connection speed, age, interests, etc) to make a personalised web experience. If only two elements are collected and both are used, the PI score may be 1.00 , but it 
typically would mean that the company is performing market segmentation rather than personalisation. If a PI is above 0.75 , then the company is making the most of the information they are collecting. When collecting more and more elements, you are able to classify users into more and more clusters. That is where broad segmentation moves towards personalisation. That is where you start to foster a customer relationship and turn it into a loyalty relationship, significantly raising the cost for your customer to switch to another vendor. If a company's PI is less than 0.30 , then you are collecting more information than you are using. For companies that are collecting information but are not using it to benefit their customers, this can adversely affect customers' experience. Companies should use the data they have more efficiently, as well as cut down on how much explicit data they are trying to collect.

\section{FUTURE RESEARCH}

No one indicator will tell a company whether they should implement a personalisation strategy. Rather, a combination of the elements will be integral in ensuring success through personalisation. Questions to consider when incorporating personalisation into the CRM strategy are:
Future considerations for revenue generation should include metrics such as:

(1) Higher conversion rate from browser (prospect) to buyer (customer)

(2) Higher customer lifetime value/return by customer

(3) Reduced customer attrition/longer duration of customer relationship

(4) More transactions/products sold

(5) Higher repeat purchase rate

(6) Higher average size of transaction/more intense product usage

\section{CONCLUSION}

The use of personalisation has grown at a phenomenal rate. Whereas personalisation previously meant a login screen and a greeting by name at the home page, personalisation now infers CRM. Beyond simple identification, personalisation now entails the capture of user data through explicit and implicit means. There are various types of personalisation technologies; however, the cases reveal an inter-functional and departmental alignment before implementing personalisation to maximise benefits. The value of personalisation is clear, given the magnitude of customer knowledge available. Unfortunately, measuring the value of personalisation qualitatively or quantitatively is not so simple.

\begin{tabular}{|c|c|}
\hline $\begin{array}{l}\text { Company's products/services - } \\
\text { Revenue potential - }\end{array}$ & $\begin{array}{l}\text { What are the product/services you have relative to the marketplace? } \\
\text { What is the value of the product you offer, what is the frequency of } \\
\text { replacement by an individual consumer? }\end{array}$ \\
\hline Switching costs - & $\begin{array}{l}\text { What is the switching cost to the customer? Does it cost them personal time } \\
\text { as well as money? }\end{array}$ \\
\hline Industry concentration - & $\begin{array}{l}\text { How easy is it to find a replacement for your product/service? How saturated } \\
\text { is the market in your area? }\end{array}$ \\
\hline Knowledge of customer - & $\begin{array}{l}\text { What is your ability to influence your customers' behaviours such as } \\
\text { frequency, loyalty and purchase decisions? }\end{array}$ \\
\hline
\end{tabular}

Moving to improve bottom-line and top-line numbers such as revenue generation would be important towards identifying quantitative benefits of personalisation.
Lessons learned indicate that companies should approach personalisation from an inter-functional as opposed to a 'silo' implementation to reap maximal benefits. 
Personalisation must be integrated as part of a CRM approach. Likewise, personalisation must disseminate information that 'anticipates relevant intent' for customers. Lessons learned from the various cases also reveal that there is a need for additional metrics of personalisation as it is implemented as part of a CRM strategy. Both $b 2 b$ and b2c companies can benefit from personalisation. For example, Cisco and American Airlines reported quantifiable cost savings and ROI benefits. There are disparities in the magnitude of personalisation benefits; however, at least two conclusions can be drawn: one, the value of personalisation can be measured through overall cost reductions (eg online technical support), but not necessarily revenue increases and two, personalisation can be linked to the measurement of a company's financial benefits.

Personalisation is the continuous process of collecting, analysing and using information about the end-user in order to improve the productivity and value of their interaction with the organisation. The PI indicator implies that companies would do well to collect only those critical data pieces of information from customers to increase the customer experience; otherwise, personalisation will negate the benefits of a CRM strategy.

\section{References}

1 Eads, S. (2000) 'The web's still-unfulfilled personalization promise', BusinessWeek, 4th August, 2000.

2 Jackson, T. W. (2005) 'CRM from art to science', Database Marketing \& Customer Strategy Management, Vol. 13, No. 1, pp. 76-92.

3 Andrews, W. and Votsch, V. (2001) 'Two dimensions of personalization: Method and time', Gartner Advisory, Research Note, 15th January, 2001.

4 Personalisation Consortium (May 2005) Personalised consortium. Retrieved on 12th May, 2005 from: http://www.moskalyuk.com/links/stats.htm.

5 Kotler, P. (1994) 'Marketing management', PrenticeHall, Inc, New Jersey.

6 Fox, T. and Steve, S. (2001) 'Customer relationship management: Delivering the benefits', (3/26/2001) retrieved on 30th May, 2005 from: http://crm. ittoolbox.com/documents/document.asp?i=1271.

7 Peppers, D. and Rogers, M. (1999) 'Enterprise one to one', Random House, New York, NY.

8 Forrester (1998) 'Better customer service propels personalization', Forrester Research, 31st July, 1998.

9 InfoWorld Media Group, Inc. (1998) 'Web marketing gets personal: Personalisation tools and the web', InfoWorld, 12th January, 1998.

10 Billsus, D. and Pazzani, M. (2002) 'A hybrid user model for news story classification', Proc. 7th Int'l Conf. on User Modeling, (UM i99), available at: http://citeseer.nj.nec.com/billsus99hybrid.html.

11 Mobasher, B., Cooley, R. and Srivastava, J. (2000) 'Automatic personalization based on web usage', Communications of the ACM, Vol. 43, No. 8 , pp. $142-151$.

12 Perkowitz, M. and Etzioni, O. (2000) 'Towards adaptive web sites: Conceptual framework and case study', Artificial Intelligence, Vol. 118, No. 1/2, pp. $245-275$.

13 Accenture (2000) Cisco Systems, Inc. Case Study. May 2000.

14 Jacoby, D. (2007) 'Personalisation: Transforming the Way Business Connects', The Economist Intelligence Unit, New York, NY.

15 Valimaka, M. (2005) 'Customer Relationships in Focus', Hansa Press, Germany.

16 Witt, C. E. (2005) 'Package flow technology at UPS', Material Handling Management, Vol. 60, No. 4, pp. 18-19.

17 McGregor, J., Jespersen, F. F., Tucker, M. and Dean, F. (2006) 'Customer service champs', Business Week, 5th March, 2007.

18 Op cit.

19 Harris Interactive (2006) National Corporation Reputation Survey, Harris Market Research.

20 American Airline (2007) retrieved on 1st July, 2007 from: http://www.nadelphelan.com/pdfs/AA.pdf.

21 American Airlines (2007) retrieved on 13th July, 2007 from: http://www.aa.com/content/aboutUs/ pressGuide/factSheet.jhtml.

22 Epps, S. R. (2007) '2007 US airline web site rankings', Forrester Research, Dallas, TX.

23 Business Wire, Inc (1999) 'Press release: Art technology group teams with documentum to deliver robust document and relationship management solution', Business Wire, 25th January, 1999.

24 Levi Strauss \& Co (1998) Press Release: Online Store Opens its Virtual Doors. September 1998.

25 One-to-One Web Marketing E-News (1998) Personalisation, Privacy and Payoff. October 1998.

26 Accenture (2000) Dell Computer Company Case Study. May 2000

27 American Airline (May 2005) “American Airlines' AA.com Gets Personal” (April 1999) retrieved on 31st May, 2005: http://cci.mccombs.utexas.edu/ research/case/aa.htm.

28 Net Genesis (2000) 'E-Metrics business metrics for the new economy', SPSS, 31st December, 2000. 